DOI : 10.15740/HAS/IJPP/12.2/188-196

\title{
Insect pests of citrus and their management
}

\author{
Rupak Kr. Nath*1 and Sikha Deka ${ }^{2}$
}

${ }^{1}$ Department of Entomology, SCS College of Agriculture, Assam Agricultural University, Rangamati, Dhubri (Assam) India

${ }^{2}$ Citrus Research Station (AAU), Tinsukia (Assam) India

\section{ARITCLE INFO}

Received : 29.08 .2019

Accepted : 30.09 .2019

\section{KEY WORDS :}

Insect, Pests, Citrus
*Corresponding author:

Email : rupaknath09@gmail.com

\begin{abstract}
Citrus is one of the most important fruits and one of the largest fruit industries in the world, grown in more than 52 countries around the world. In India, 250 species of insects and mites have been reported infesting different species of citrus. Trunk borer, Leaf miner, citrus psylla, red scale, mealy bugs and aphids were recorded as major pests of khasi mandarin oranges in NEH region of India. These pests significantly contribute towards the citrus decline in the region. For management of these pests, diagnosis of the causes of decline, the rejuvenation schedule may be formulated with multi-disciplinary approach. More information is needed on some of the key elements required for environmentally friendly management Biological control through augmentation and conservation of parasitoids integrated with other non-pesticide measures need to be tested with holistic approach in citrus. More attention should be given to the knowledge of the biology and ecology of parasitoid species. Bio-pesticides, including botanicals, can offer a safe and effective alternative to conventional insecticides for controlling the pest within an integrated pest management programme.
\end{abstract}

How to view point the article : Nath, Rupak Kr. and Deka, Sikha (2019). Insect pests of citrus and their management. Internat. J. Plant Protec., 12(2) : 188-196, DOI : 10.15740/HAS/IJPP/ 12.2/188-196, Copyright@ 2019: Hind Agri-Horticultural Society. 